\title{
İn Vitro Fertilizasyon ile Gebe Kalan Hastaların Gebelik Sonuçlarının Değerlendirilmesi: Tersiyer Merkez Deneyimi
}

\section{Evaluation of Pregnancy Results of in Vitro Fertilization Patients: A Tertiary-Center Experience}

\author{
Şeyhmus TUNÇ ${ }^{1}$, Ilgın TÜRKÇÜOĞLU², Süleyman Cemil OĞLAK ${ }^{1}$ \\ ${ }^{1}$ Sağlık Bilimleri Üniversitesi, Diyarbakır Gazi Yaşargil Eğitim ve Araştırma Hastanesi, Kadın Hastalıkları ve Doğum Kliniği, Diyarbakır \\ ${ }^{2}$ Sanko Üniversitesi Tıp Fakültesi, Kadın Hastalıkları ve Doğum Anabilim Dalı, Gaziantep
}

\section{$\ddot{\mathbf{O z}}$}

Bu çalısmada in vitro fertilizasyon (IVF) ile gebe kalan hastaların gebelik sonuçlarının retrospektif olarak değerlendirilmesi amaçlanmıştır. Nisan 2009 ile Şubat 2013 tarihleri arasında doğum yapan 6369 gebenin kaydı retrospektif olarak değerlendirildi. Kontrollü Ovaryan Hiperstimulasyon-IVF/ICSI ile gebe kalan 151 olgu ile çalışma grubu olușturuldu. Kontrol grubu kendiliğinden gebe kalan hastalardan sistematik örnekleme ile seçilerek oluşturuldu (262 olgu). Her iki grubun sonuçları değerlendirildi. Çalışma grubunda çoğul gebelik, preterm doğum, preterm prematür membran rüptürü, malprezentasyon, gestasyonel diyabet oranları daha fazlaydı. Ortalama doğum haftası ve ortalama doğum ağırlığı kontrol grubunda daha fazlaydı. Her iki grupta yenidoğanın kan gazı $\mathrm{pH}$ değerleri, 1. ve 5. dakika Apgar skoru açısından istatistiksel farklılık yoktu. Yenidoğan yoğun bakım ünitesine yatış oranı ve perinatal ölüm oranı çalışma grubunda daha fazlaydı. Yardımcı üreme teknikleri ile meydana gelen gebeliklerde maternal ve fetal riskler daha fazladır. Tüm bu riskler gebelik sürecinin ve yenidoğanın yakın takibini gerektirmektedir.

Anahtar Kelimeler: Çoğul Gebelik, Erken Doğum, Perinatal Ölüm

\section{Giriş}

Yardımcı üreme teknikleri (YÜT) ile oluşan gebeliklerin prevalansı her geçen gün artmaktadır. Eskiden YÜT ile elde edilen gebeliklerin sonuçları incelenirken en çok önemsenen husus canlı doğum oranıyd. Günümüzde ise artık YÜT ile oluşan gebeliklerin seyrine, doğum öncesi ve sonras1 sorunlarına ve olası kötü sonuçları üzerine yoğunlaşılmaktadır.

YÜT ile oluşan gebelikler, beklentisi yüksek gebeliklerdir ve bu beklenti hem hastada hem de hekimde kaygı oluşturmaktadır. Dolayısıyla hekim tarafından gebelik sürecinin olabildiğince kontrol altında tutulması oldukça önemlidir.

YÜT ile oluşan gebeliklerde artmış maternal ve fetal riskler ve artmış sezeryan oranları hala

$\begin{array}{ll} & \text { ORCID No } \\ \text { Şeyhmus TUNÇ } & \text { 0000-0002-7 } \\ \text { Ilgı̈ TÜRKÇÜOĞLU } & \text { 0000-0002-834 } \\ \text { Süleyman Cemil OĞLAK } & 0000-0001-763 \\ & \\ \text { Başvuru Tarihi / Received: } & 09.06 .2020 \\ \text { Kabul Tarihi / Accepted : } & 15.07 .2020\end{array}$

Adres / Correspondence : $\quad$ Süleyman Cemil OĞLAK Sağlık Bilimleri Üniversitesi, Diyarbakır Gazi Yaşargil Eğitim ve Araştırma Hastanesi, Kadın Hastalıkları ve Doğum Kliniği, Diyarbakır

e-posta / e-mail sampson_21@hotmail.com

\begin{abstract}
In this study, we aimed to retrospectively evaluate the pregnancy outcomes of in vitro fertilization (IVF) patients. The records of 6369 pregnant women who gave birth between April 2009 and February 2013 were evaluated retrospectively. 151 Patients who were conceived Controlled Ovarian Hyperstimulation-IVF/ICSI were included in the study group. The control group was formed by a systematic sampling of spontaneous pregnant cases (262 cases). The results of both of the groups were evaluated. Multiple pregnancies, preterm delivery, preterm premature rupture of membranes, malpresentation, and gestational diabetes rates were significantly higher in the study group. Mean gestational week at birth and mean birth weight was significantly higher in the control group. There was no statistically significant difference in blood $\mathrm{pH}$ values and Apgar score of the 1 and 5 minutes of the newborn in both groups. Neonatal intensive care unit admission and perinatal mortality rates were significantly higher in the study group. Both maternal and fetal risks are increased in pregnancies with assisted reproductive techniques. All these risks require close monitoring of the mother and newborn during pregnancy and the postpartum period.

Keywords: Multiple Pregnancy, Preterm Birth, Perinatal Death
\end{abstract}

tartışılmaya devam etmektedir (1). Hastanın subfertil olması durumu bile, hastanın gebe kalmak için tedavi alıp almadığından bağımsız olarak, kötü gebelik sonuçlarının oluşumuna katkıda bulunabilmektedir. Çalışmalarda tedavisiz gebe kalan subfertil olgularda kötü gebelik sonuçları genel populasyona göre daha fazla görülmüştür (2). Tüm riskler YÜT ile tedaviye başlamadan önce hasta ve eşi ile konuşulmalı, aileden bilgilendirilmiş onam alınmalidir.

$\mathrm{Bu}$ çalışmada in vitro fertilizasyon (IVF) ile gebe kalan hastaların gebelik sonuçlarınının retrospektif olarak değerlendirilmesi amaçlanmıştır.

\section{Gereç ve Yöntem}

$\mathrm{Bu}$ çalışma, İnönü Üniversitesi Tıp Fakültesi Kadın Hastalıkları ve Doğum Bölümüne Nisan 2009-Şubat 2013 tarihleri arasında doğum yapmak üzere başvuran 6369 hastanın verileri, 22.08.2019 tarih ve E.16356 numaralı onayı takiben, hastanenin kayıt sisteminden retrospektif olarak taranarak gerçekleştirildi. Kontrollü ovaryan hiperstimülasyon/IVF-ICSI ile oluşmuş 151 gebe çalışma grubuna dahil edildi. Kendiliğinden gebe kalmış ve bu süreç zarfında doğum yapmış 6218 gebeye sıra numarası başvuru tarihine göre verildi. Sistematik örnekleme ile her 1/23. olgu (6218/262) 
seçilerek toplam 262 olgu kontrol grubuna dahil edilmiştir.

Her iki gruptaki hastalar anne yaşı, tekil-çoğul gebelik, başvuru anındaki gebelik haftası, gebelik öyküsü (gravida, parite, abortus, dilatasyon/küretaj), eşlik eden kronik hastalık varlığı, erken doğum, preterm prematür membran rüptürü (PROM), oligohidroamniyozis, intrauterin gelişme kısıtlılığ (IUGR), gestasyonel diyabet, polihidroamniyozis, gestasyonel hipertansif hastalık, malprezentasyon, intrauterin fetal ölüm, sezaryen oranı ve sezeryan endikasyonları açısından karşılaştırıldı. PPROM, 37. gebelik haftasından önce amniyotik membranların yırtılması olarak tanımlandı (3). IUGR, fetal biparietal çap, baş çevresi, karın çevresi ve femur uzunluğunun sonografik ölçümlerine göre beklenen doğum ağırlığının $<3$ persentil olması şeklinde tanımland $1(4,5)$. Gestasyonel hipertansif hastalık teşhisi ACOG kriterlerine göre konuldu (6). Gestasyonel diyaber teşhisi IDPSG kriterlerine göre konuldu (7). Her iki gruptaki yenidoğanlar ise 1.ve 5. dakika Apgar skoru, cinsiyet, doğum ağırlığı, anomali varlığı, umbilikal kordon $\mathrm{pH}$ değeri, umbilikal kordon baz açığı değeri, yenidoğan yoğun bakım ünitesine (YDYBÜ) yatış oranı ve perinatal ölüm oranı açısından karşılaştırıldı.

Verilerin istatistiksel analizinde SPSS 18.0 programı kullanıldı. Kategorik değişkenler sayı ve yüzde, sayısal değişkenler ortalama ve standart sapma şeklinde sunuldu. Grupların kategorik ölçümler açısından karşılaştırılırken Pearson ki-kare testi ve Fisher's exact test uygulandi. Sayisal ölçümlerin normal dağılım varsayımını sağlayıp sağlamadığı Kolmogrov Smirnov testi ile değerlendirildi. Varsayımların sağlanması halinde bağımsı gruplarda $\mathrm{T}$ testi, varsayımların sağlanmaması halinde ise Mann Whitney $U$ testi uygulandı. Tüm testlerde $\mathrm{p}<0.05$ istatistiksel olarak anlamlı kabul edildi.

\section{Bulgular}

Çalışmaya YÜT ile gebe kalan 151 hasta ile kendiliğinden gebe kalan 262 hasta dahil edildi. YÜT ile gebe kalan hastaların yaş ortalaması (32.2 \pm 6.06$)$ kendiliğinden gebe kalan gruba göre $(28.7 \pm 5.84)$ anlamlı olarak daha yüksekti $(\mathrm{p}=0.0001)$. Çoğul gebelik oranı YÜT ile gebe kalan grupta (\%53), kendiliğinden gebe kalan gruba (\%5) göre daha yüksekti $(\mathrm{p}=0.0001)$.

YÜT ile gebe kalan hastalarda doğumdaki gebelik haftası kontrol grubuna göre anlamlı olarak daha düşük bulundu ( $p=0.0001)$. YÜT ile gebe kalan grupta erken preterm ( $\leq 33$ hafta) doğum oranı en fazla görülürken, kontrol grubunda miyadında doğum oranı en fazla görüldü ( $\mathrm{p}=0.001)$.

Her iki grubun perinatal sonuçları Tablo 1'de gösterilmiştir. YÜT ile gebe kalan grupta PPROM kontrol grubuna oranla anlamlı olarak daha fazla bulundu $(\mathrm{p}=0.036)$.
Her iki gruptaki fetal anomalilerin oranı gruplar arasında benzerdi (Tablo 2). Sezeryan ile doğum oranı YÜT ile gebe kalan grupta (\%93.6) kendiliğinden gebe kalan gruba (\%62.2) göre daha fazla saptand $1(p=0.0001)$. YÜT ile gebe kalan grupta sezaryen endikasyonlarının büyük çoğunluğunu (\%41.7) çoğul gebelik oluşturmaktaydi.

Ortalama doğum kilosunun YÜT ile gebe kalan grupta, kontrol grubuna göre anlamlı olarak daha düşük olduğu görüldü $(\mathrm{p}=0.0001)$. Her iki grup, yenidoğanın 1. ve 5. dakika Apgar skoru, umbilikal kordon $\mathrm{pH}$ 'sı ve baz açı̆̆ karşılaştırıldığında, istatistiksel olarak anlamlı bir farklılık görülmedi. YÜT ile gebe kalan grupta YDYBÜ'ye yatış oranı $(p=0.0001)$ ve perinatal ölüm oranı $(\mathrm{p}=0.016)$, kontrol grubuna göre anlamlı olarak daha fazla görüldü. Neonatal sonuçların dağılımı Tablo 3 'te gösterilmiştir.

\section{Tartışma}

YÜT gebeliklerinde normal popülasyona oranla, hem ikiz gebelik hem de üçüz gebelik oranları artmaktadır (1). Bu çalışmada YÜT ile gebe kalan hastaların \%53'ünde çoğul gebelik mevcutken bu oran kontrol grubunda \%5'ti.Çalışmamızdaki yüksek çoğul gebelik oranı, hastanemizin yenidoğan yoğun bakım hizmeti veren ileri merkez hastane olması ile açıklanabilir. Çoğul gebelik oranını azaltmak için tek embriyo transferi önerilmektedir. Tek embriyo transferi yapılanlarla birden fazla embriyo transferi yapılanlar karşılaştırıldığında, tek embriyo transferi yapılanlarda canlı doğum oranlarının daha yüksek olduğu bildirilmektedir (8).

Yakın zamanda yapılan bir çalışmada, IVF/ICSI ile gebe kalanlarda ortalama doğum haftası anlamlı olarak düşük, erken doğum ve PPROM oranları anlamlı olarak yüksek bulunmuştur (8). Halliday'in yaptığı derlemede, IVF gruplarında erken doğum riskinin 2 kat arttı̆̆ saptanmıştır (9).Helmerhorst ve arkadaşlarının, 1985-2002 yılları arasında yapılmış 25 çalışmayı içeren derlemesinde, YÜT ile oluşmuş tekil gebeliklerde erken doğum riskinin 2.04 kat, çoğul gebeliklerde erken doğum riskinin $1.07 \mathrm{~kat}$ arttığı görülmüştür (10). Bu çalışmada YÜT ile gebe kalanlarda, kendiliğinden gebe kalanlara göre ortalama doğum haftası daha düşük, erken-geç preterm doğum ve PPROM oranları daha fazla bulundu. Çoğul gebeliğin erken doğum oranına etkisini dışlamak için sadece tekil gebelikler karşılaştırıldığında, ortalama doğum haftası YÜT ile gebe kalanlarda anlamlı olarak düşük saptandı $(\mathrm{p}=0.011)$. Dolayısıyla YÜT'nin uygulanması erken doğum için bir risk faktörü olduğu söylenebilir.

Yapılmış çalışmalarda, YÜT ile gebe kalanlarda hem tekil hem de ikiz gebeliklerde IUGR oranları kendiliğinden gebe kalan grupla benzer bulunmuştur $(11,12)$. Polihidramniyos ve oligohidramniyos oranları da her iki grupta benzerdir (13). Çalışmamızda iki grupta da IUGR, polihidramnios 
ve oligohidramniyos oranları benzer olarak saptanmıştır. Yakın zamanda yapılmış bir çalışmada YÜT ile gebe kalanlarda gestasyonel diyabet sıklığı ve tedavide kullanılan günlük toplam insülin dozları

Tablo 1. Perinatal sonuçların dağglımı daha yüksek bulunmuştur (14). 2004 yılında yapılan bir çalışmada, gebeliğe bağlı hipertansif hastalıkların sıklığı açısından, YÜT ile ve

\begin{tabular}{|c|c|c|c|}
\hline & YÜT (n: 151) & Spontan (n: 262) & $\mathbf{p}$ \\
\hline Preterm doğum (n, \%) & $102(\% 67.5)$ & $98(\% 37.4)$ & 0.0001 \\
\hline$<34$ hafta & $55(\% 36.4)$ & $42(\% 16)$ & \\
\hline 34-37 hafta & $47(\% 31.1)$ & $56(\% 21.3)$ & \\
\hline Prematür preterm membran rüptürü (n, \%) & $30(\% 19.9)$ & $32(\% 12.2)$ & 0.036 \\
\hline İntrauterin gelişme geriliği $(n, \%)$ & $10(\% 6.6)$ & $25(\% 9.5)$ & 0.305 \\
\hline Oligohidroamniyoz (n, \%) & $12(\% 7.9)$ & $22(\% 8.4)$ & 0.873 \\
\hline Polihidroamniyoz (n, \%) & $4(\% 2.6)$ & $3(\% 1.1)$ & 0.265 \\
\hline Gestasyonel Diyabet Mellitus (n, \%) & $29(\% 19.2)$ & $23(\% 8.8)$ & 0.002 \\
\hline Hipertansif hastalık (n, \%) & $21(\% 13.9)$ & $30(\% 11,5)$ & 0.464 \\
\hline Malprezentasyon (n, \%) & $42(\% 27.8)$ & $26(\% 9.9)$ & 0.0004 \\
\hline İntrauterin fetal ölüm (n, \%) & $3(\% 2)$ & $11(\% 4.2)$ & 0.059 \\
\hline
\end{tabular}

Tablo 2. Fetal anomalilerin dağılımı

\begin{tabular}{cccc}
\hline & YÜT (n: 151) & Spontan(n: 262) & p \\
\cline { 2 - 4 } Renal anomali (n, \%) & $2(\% 1.3)$ & $0(\% 0)$ & 0.214 \\
Diyafragma hernisi (n, \%) & $1(\% 0.7)$ & $0(\% 0)$ & 0.463 \\
Kalp anomalisi (n, \%) & $1(\% 0.7)$ & $2(\% 0.8)$ & 1.000 \\
Nöral tüp defekti (n, \%) & $0(\% 0)$ & $5(\% 1.9)$ & 0.065 \\
\hline
\end{tabular}

Tablo 3. Neonatal sonuçların dağılımı (*: Ortalama \pm standart sapma)

\begin{tabular}{cccc}
\hline & YÜT (n: 237) & Spontan (n: 275) & p \\
\cline { 2 - 4 } Doğum kilosu(g) * & $2086 \pm 817$ & $2723 \pm 796$ & 0.0001 \\
< 1500 gr (n, \%) & $49(\% 20.7)$ & $21(\% 7.6)$ & 0.0001 \\
1500-2500 gr (n, \%) & $113(\% 47.7)$ & $78(\% 27.4)$ & $176(\% 64)$ \\
2500 gr > (n, \%) & $75(\% 31.6)$ & $6.70 \pm 1.94$ & 0.427 \\
Apgar 1.dk* & $6.83 \pm 1.72$ & $8.61 \pm 2.26$ & 0.298 \\
Apgar 5.dk* & $8.81 \pm 1.83$ & $7.28 \pm 0.14$ & 0.356 \\
Kord pH* & $7.30 \pm 0.10$ & $-5.77 \pm 5.95$ & 0.525 \\
Baz açı̆̆ı* & $-5.3 \pm 5.07$ & $61(\% 22.2)$ & 0.0001 \\
YDYBÜ'ye yatıș(n, \%) & $94(\% 39.7)$ & $17(\% 6.2)$ & 0.016 \\
Perinatal ölüm (n, \%) & $29(\% 12.2)$ & & \\
\hline
\end{tabular}

kendiliğinden gebe kalanlarda fark görülmemişken 2016 yılında yapılan bir çalışmada gebeliğe bağlı hipertansiyon riski YÜT ile gebe kalan grupta daha yüksek bulunmuştur $(13,15)$. Bu çalışmada gestasyonel diabet oranı YÜT ile gebe kalan grupta daha yüksek olarak bulundu. Gebeliğe bağl1 hipertansif hastalıklar açısından ise her iki grup arasında fark görülmedi.

Yapılan birçok çalışmada, YÜT ile gebe kalanlarda doğumda prezentasyon bozukluğu (malprezentasyon) sıklığı $\operatorname{artmıştır~(9).~YÜT~ile~gebe~}$ kalanlarda hem acil sezeryan hem de elektif sezeryan oranları artmaktadır (16). Bunun nedeni, YÜT ile gebe kalanlarda çoğul gebelik oranlarının, erken doğum ve malprezentasyon sıklığının artmasına bağlı olabilir. Ayrıca bu gebelikler yüksek beklentili gebelikler olduğundan elektif sezeryan oranları artmıştır. Bu çalışmada YÜT ile gebe kalanlarda kendiliğinden gebe kalan gruba göre, malprezentasyon oranında artış ve sezaryenle doğum oranında artış saptandi.

Yapılan çalışmalarda YÜT ile oluşmuş tekil gebeliklerde düşük doğum ağırlığı için göreceli risk oranı 1.62-1.8, çok düşük doğum ağırlığı için göreceli risk oranı 1.79-3.78 olarak saptanmıştır (9,
10, 17). Çoğul gebeliklerde düşük doğum ağırlığı için göreceli risk oranı 1.03-1.23, çok düşük doğum ağırlığı için göreceli risk oranı 1.07-1.8olarak bulunmuştur $(10,12)$. Çalışmamızda YÜT ile gebe kalanlarda düşük doğum ağırlığı oranı 1.7 kat, çok düşük doğum ağırlığı oranı 2.7 kat artmış olarak bulunmuştur.

Çalışmalarda YÜT ile oluşmuş hem tekil hem de çoğul gebeliklerde YDYBÜ'ye yatış oranının arttığ görülmüştür $\quad(9,10,13,18)$. Bazı çalışmalarda perinatal ölüm oranları her iki grupta benzer bulunmuş olsa da $(13,15)$, daha geniş hasta serilerine sahip çalışmalarda, YÜT ile oluşmuş tekil ve çoğul gebeliklerde perinatal ölüm oranları yaklaşık 2 kat artmış olarak saptanmıştır $(9,18)$. Çalışmamızda YÜT ile gebe kalanlarda spontan gebeliklere göre YDYBÜ'ye yatış oranları 1.78 kat, perinatal ölüm oranları 1.96 kat artmış olarak saptanmıştır.

Klemetti ve arkadaşlarının yaptığı geniş hasta serili bir çalışmada YÜT ile oluşmuş tekil gebeliklerde major konjenital malformasyon sıklığının 1.3 kat arttığı görülmüştür (19). Başka birçok yayında, YÜT ile gebe kalanların fetuslarında hipospadias haricindeki genitoüriner anomaliler, gastrointestinal anomaliler, yarık damak, yarık 
dudak, nöral tüp defektleri, kas-iskelet sistemi anomalileri, kromozomal defektler ve kardiyovasküler anomalilerin daha fazla görüldüğü bildirilmiştir $(19,20)$. Bu çalışmada her iki grupta hem tekil hem de çoğul gebeliklerde fetal malformasyon oranları benzer olarak tespit edildi. Bunun nedeninin çalışmaya dahil edilen hastaların doğum için hastaneye başvuran hastalardan seçilmiş olması ve abortusla sonuçlanan veya fetal anomali nedeni ile gebeliğin erken haftalarında termine edilen gebeliklerin çalışmaya dahil edilmemesine bağlı olduğunu düşünmekteyiz. Ancak daha geniş serili hasta gruplarının olduğu çalışmalara ihtiyaç olduğunu düşünmekteyiz.

Sonuç olarak, YÜT ile elde edilen gebeliklerde maternal ve fetal riskler artmıştır. Tüm bu riskler gebelik, doğum süreci ve doğum sonrasında anne ve yenidoğanın yakın takibini gerektirmektedir. Oluşabilecek tüm komplikasyonlar gebelik öncesinde aile ile konuşularak aydınlatılmalı ve buna yönelik olarak onam alınmalıdır.

Etik Kurul Onayı: İnönü Üniversitesi Tıp Fakültesi 22.08.2019 tarih ve 16356 numara ile onay alınmıştır

\section{Kaynaklar}

1. Lei LL, Lan YL, Wang SY, Feng W, Zhai ZJ. Perinatal complications and live-birth outcomes following assisted reproductive technology: a retrospective cohort study. Chin Med J (Engl). 2019;132(20):2408-16

2. Messerlian C, Maclagan L, Basso O. Infertility and the risk of adverse pregnancy outcomes: a systematic review and meta-analysis. Hum Reprod. 2013;28(1);125-37.

3. Behram M, Oğlak SC, Başkıran Y, Süzen Çaypınar S, Akgöl S, Tunç Ş, et al. Maternal serum IL-22 concentrations are significantly upregulated in patients with preterm premature rupture of membranes. Ginekol Pol. 2021;92(9):631-6.

4. Oğlak SC, Bademkıran MH, Obut M. Predictor variables in the success of slow-release dinoprostone used for cervical ripening in intrauterine growth restriction pregnancies. J Gynecol Obstet Hum Reprod. 2020;49(6):101739.

5. Behram M, Oğlak SC, Dağ İ. Circulating levels of Elabela in pregnant women complicated with intrauterine growth restriction. J Gynecol Obstet Hum Reprod. 2021;50(8):102127.

6. Behram M, Oğlak SC, Doğan Y. Evaluation of BRD4 levels in patients with early-onset preeclampsia. J Gynecol Obstet Hum Reprod. 2021;50(2):101963.

7. Oğlak SC, Obut M. Expression of ADAMTS13 and PCNA in the placentas of gestational diabetic mothers. Int J Morphol. 2021;39(1):38-44.
8. Fujimoto A, Morishima K, Harada M, Hirata T, Osuga Y, Fujii T. Elective single-embryo transfer improves cumulative pregnancy outcome in young patients but not in women of advanced reproductive age. $\mathbf{J}$ Assist Reprod Genet. 2015;32(12):1773-9.

9. Dobrosavljevic A, Rakic S, Mihajlovic S. Risk of spontaneous preterm labor in pregnancies achieved by in vitro fertilization and complicated with severe form of ovarian hyperstimulation syndrome: A case control study. Pak J Med Sci. 2019;35(4):923-8.

10. Halliday J. Outcomes of IVF conceptions: are they different? Best Pract Res Clin Obstet Gynaecol. 2007;21(1):67-81.

11. Helmerhorst FM, Perquin DA, Donker D, Keirse MJ: Perinatal outcome of singletons and twins after assisted conception: a systematic review of controlled studies. BMJ. 2004;328:261.

12. Dhalwani NN, Boulet SL, Kissin DM, et al. Assisted reproductive technology and perinatal outcomes: conventional versus discordant-sibling design. Fertil Steril. 2016;106(3):710-6.

13. Qin JB, Wang $H$, Sheng $X$, Xie Q, Gao S. Assisted reproductive technology and risk of adverse obstetric outcomes in dichorionic twin pregnancies: a systematic review and meta-analysis. Fertil Steril. 2016;105(5):1180-92.

14. Manoura A, Korakaki E, Hatzidaki E, Bikouovarakis S, Papageorgiou M, Giannakopoulou C: Perinatal outcome of twin pregnancies after in vitro fertilization. Acta Obstet Gynecol Scand. 2004;83:1079-84.

15. Kouhkan A, Khamseh ME, Pirjani R, et al. Obstetric and perinatal outcomes of singleton pregnancies conceived via assisted reproductive technology complicated by gestational diabetes mellitus: a prospective cohort study. BMC Pregnancy Chilbirth. 2018;18(1):495.

16. Qin J, Liu X, Sheng X, Wang H, Gao S. Assisted reproductive technology and the risk of pregnancy-related complications and adverse pregnancy outcomes in singleton pregnancies: a meta-analyses of cohort studies. Fertil Steril. 2016;105(1):73-85.

17. Neumann K, Cirkel C, Rody A, Beyer DA. Do ART patients face higher $\mathrm{C}$-section rates during their stage of delivery: A German monocenter experience. Arch Gynecol Obstet. 2017;259(2):481-5.

18. Declercq E, Luke B, Belanoff C, et al: Perinatal outcomes associated with assisted reproductive technology: the Massachusetts Outcomes Study of Assisted Reproductive Technologies (MOSART). Fertil Steril. 2015;103(4):888-95.

19. Sullivan-Pyke CS, Senapati S, Mainigi MA, Barnhart KT. In Vitro fertilization and adverse obstetric and perinatal outcomes. Semin Perinatol. 2017;41(6):345-53.

20. Klemetti R, Gissler M, Sevón T, Koivurova S, Ritvanen A, Hemminki E. Children born after assisted fertilization have an increased rate of major congenital anomalies. Fertil Steril. 2005;84(5):1300-7.

21. Reefhuis J, Honein MA, Schieve LA, Correa A, Hobbs CA, Rasmussen SA; National Birth Defects Prevention Study. Assisted reproductive technology and major structural birth defects in the United States. Hum Reprod. 2009;24:360-6. 